the complete story and an interview with a close relative may add a revealing new dimension to the case. We also see what happens when the therapist asks the patient to keep a diary of her symptoms. At the end of the four assessment interviews the therapist gives the patient the choice of four options (and makes her chose)-no treatment, treatment aimed at improving her self confidence, marital therapy and a behavioural treatment of agrophobia. I won't tell you which one she chooses. Nor do we know how well she does!

It is always useful to have a 'typical case' available for teaching and I would be happy to use this one. But how? I don't think it is really a suitable tape for private studynot enough guidance is given. I can see it of use as a "lecture aid' but it is too long to run without a break. I would want a transcript available and stop it every so often to ask the group what they thought.

Interviews don't make gripping television and although the recording is of a high standard I do think more could have been done to make it visually interesting. For example, it would be possible to add greater impact by better use of the zoom lens, cut-away or big close-up. The actor roleplaying the patient had a difficult task. I didn't find her very believable and I think she would have benefited from more direction.

To sum up then, a useful tape for illustrating a clinical history of agrophobia but the lecturer would need some familiarity with the tape to get the best out of it. A transcript or detailed handout would be useful.

Production: Department of Psychology, Birmingham University, and Paul Morby. Purchase price: $£ 100$ (VHS format). Distributor: TV and Film Unit, University of Birmingham, P.O. Box 363, Birmingham B15 2TT.

ANDrew Macaulay St George's Hospital, London

\section{View from the Bar (UK, 1984, 17 mins)}

This is a 17 minute recording made for use by the Navy. It is suggested that following its showing a Naval Officer might comment upon it, and suggest that his fellow officers may care to look out for the symptoms outlined in the film.

The film itself goes through most of the prodromal symptoms of alcoholism and, as the title suggests, the dialogue comes from the bar-tender who illustrates his observations by reference to his customers, who in turn display the early development of alcohol dependence in all its manifestations. For example, there is a young man being urged on to drink more than he really wants by his friends, another who is mixing his drinks and anxious to get in the last round before closing time, and a third who has suffered an injury as a result of drinking. Most of the subjects are young men, but one or two women feature in the film also. The film is not over-technical and is quite clearly aimed at an audience that it hopes will identify with one or other of the early signs of alcoholism shown. To this extent I regard the film as well-made. The acting is convincing and the material covered is that part of the alcoholic slope which is least recognised as such by its victims.

This would make an excellent teaching film, particularly as these stepping-stones to established alcoholism are often as frequently unrecognised by doctors as they are by their patients.

Produced by: F. M. J. Hiles, MRCPsych (Surg. Cdr., R.N.) and Dragon Medical and Scientific Communications Ltd. Format: U-matic, VHS, Betamax and $16 \mathrm{~mm}$ film. Distributors: Stewart Film Distributors, 107-115 Long Acres, London WC2E 9NP. Purchase price: $£ 200$.

C. M. B. JARMAN St. George's Hospital, London

\section{Is Ordinary Life Pocsible? (UK, 1984, 25 mins)}

This production is about the rehabilitation of long-stay patients from a mental handicap hospital (Darenth Park) into the community, a theme that has been well explored in the past. Although it is a sympathetic and convincing programme it does not add anything new, using newsreel techniques that give little scope for imaginative editing. The dialogue is difficult to follow at times and the predominance of Northern accents is somewhat surprising in a Kent institution.

The 'good' (community) scenes are all in bright attractive colour but there is an exceptionately long tracking shot down a seemingly endless 'institutional' corridor that is deliberately inserted in black-and-white, presumably to emphasise an intended atmosphere of hopeless dreariness. This kind of visual bias should really be confined to advertising practice and it is surprising in a Health Authorities' production.

Although somewhat long, this tape would be useful to stimulate discussion in a recipient community, but its teaching value is diluted by the large number of existing films available on this theme.

Format: VHS, hire $£ 4.20$, sale $£ 40$. Producer: SE Thames RHA. Distributor: Concord Films Council, 201 Felixstowe Road, Ipswich IP3 9BJ.

T. L. Pilkington Convenor, Audio-Visual Group

\section{A Home of Our Own (UK, 1985, 20 mins)}

This video records the reactions of four young women to placement in a home in the community (Rochdale) from their residence in a large mental handicap hospital (Calderstones). It is a very professional production, well edited and with good sound. Although there is some 